\title{
Preparation and Characteristics of Humidity Controlling Characteristic Porous Ceramics with Waste Fiberglass and Waste Catalyst
}

\author{
Kae-Long Lin, Chih-Ming Ma, Huang-Mu Lo, and Ju-Ying Lan
}

\begin{abstract}
This research investigates the possibility to use humidity control porous ceramics (HCPC) to dampen indoor relative humidity variations. In this study, the following operating conditions are applied to developing HCPC products; a sintering temperature of $900-1,050^{\circ} \mathrm{C}$ and a percentage of waste fiberglass in waste catalyst of $0-40 \%$. The HCPC c samples then underwent the flexural strength test, to determine their quality in comparison to the CNS 3298 methods. Their micro-structures, their crystal structures and the volumes of their pores were determined by equilibrium moisture content and water vapor adsorption/desorption and hygroscopic sorption properties of HCPC for 48 hours. Nitrogen adsorption desorption isotherms showed a hydrophobic behavior (type $\mathrm{H}_{3}$ isotherm). The water vapor adsorption/desorption and hygroscopic sorption properties were satisfying with the JIS A1470 intensity specification of building materials $\left(>29 \mathrm{~g} / \mathrm{m}^{2}\right)$. When sintering temperature of $1000-1050$, the $\mathrm{HCPC}$ samples for the waste fiberglass contained $20-30 \%$ waste catalyst with larger pore size and higher volume could absorb a large amount of water molecules at high humidity and efficiently release it at low humidity, such that it has a large water adsorption-desorption capacity and the samples met JIS A1470 intensity specification of building materials $\left(>29 \mathrm{~g} / \mathrm{m}^{2}\right)$.
\end{abstract}

Index Terms - Waste Catalyst, humidity control, sintering, water vapor adsorption/ desorption.

\section{INTRODUCTION}

Fibreglass is widely acknowledged as a material that has major advantages over more conventional rivals, such as wood, steel and aluminium. On one hand, global production of composites materials increases every year, and it is expected to reach 10.3 Mt in 2015. Of all these composites, about $90 \%$ corresponds to thermostable composites with glass fibers [1]. Because the amount of waste fiberglass is steadily increasing year by year with the expansion of population, treatment and utilization of waste fiberglass become more important in Taiwan. The Taiwan Environmental Protection Agency reported that 11,883 tons of a waste catalyst was produced in Taiwan in 2016 [2]. The three common methods for recycling and reusing waste

Manuscript received October 20, 2016; revised May 23, 2017.

Kae-Long Lin and Ju-Ying Lan are with the Department of Environmental Engineering, National Ilan University, Ilan, Taiwan (e-mail: kllin@niu.edu.tw, doris_tension@hotmail.com).

Chih-Ming $\mathrm{Ma}$ is with the Department of Cosmetic Application \& Management, Saint Mary's Junior College of Medicine, Nursing and Management, Ilan, Taiwan (e-mail: cmma@smc.edu.tw).

Huang-Mu Lo is with the Department of Environmental Engineering and Management, Chaoyang University of Technology, Taichung, Taiwan (e-mail:hmlo@cyut.edu.tw). catalysts are landfilling, regeneration, and reuse. Landfilling is not a suitable long-term solution due to the shortage of land space as well as the environmental problems caused by garbage. Sanitary landfills are commonly used to dispose waste fiberglass and waste catalyst, but rapid urbanization has made locating suitable landfill sites increasingly difficult in Taiwan. Increasing demand for natural resources and a scarcity of environmentally acceptable solid waste disposal sites are motivating numerous municipalities in Taiwan to consider resource recovery as an alternative. Today, the reuse and recycling of waste materials after their potentialities have been detected is considered an activity that can contribute to diversify products, reduce production costs, provide alternative raw materials for a variety of industrial sectors, conserve non-renewable resources, save energy, and especially, improve public health. Current methods for recycling and reusing a waste catalyst include employing it as a Geopolymers [3], applying it in ceramic materials such as Pozzolanic Materials [4], pavement tiles [5], reusing it as a water retention of Porous Ceramics [6] and recycling it as an eco-cement [7].

To form a better glass-ceramic the crystalline behavior of these minerals needs to be encouraged by higher heat treatment temperatures. Both the porosity and water absorption rate properties are improved with increasing heat treatment temperatures [8]. The sintering process consists of a thermal treatment for coherently bonding particles, in order to enhance the strength and the other engineering properties of the compacted particles [9]. The thermal heating destroys organic residue and stabilizes inorganic material and metals by incorporating oxides from the elemental constituents into a ceramic-like material [10].

Humidity is so important to human health, and living environment, as relative humidity in door which is too high or too low has adverse effect on our living conditions [11]. Water vapor sorption properties in porous materials have attracted much attention, because they relate to a number of applications, such as gas drying, humidity control, adsorption heat pumps, and the production of fresh water from the air [12]. A humidity control porous ceramics can absorb or release moisture automatically without any power source or mechanical equipment due to its sensitivity to the variations of ambient temperature and relative humidity [13], [14]. Thus, the use of a humidity control porous ceramics is of great importance to the indoor environment, energy conservation and sustainable development of the ecological environment. The other hand, considering practical applications, especially those concerning the living environment, foods, and cosmetics, there is a strong need to develop harmless, 
low-cost porous inorganic materials with controllable water sorption capacities. The material is expected to do no harm to the environment and adsorb air pollutants. Thus, it is important to develop humidity control materials with the advantages of different components via combination. The primary consideration in setting up the humidity control porous materials for vapor adsorption-desorption applications must to control the pore size, the surface area and the pore volume, which determine the water vapor adsorption-desorption properties. This study demonstrates the feasibility of use waste fiberglass and waste catalyst produced as humidity control porous ceramics is also examined by studying flexural strength test, to determine their quality in comparison to the Chinese National Standards (CNS 3298) methods. The humidity control porous ceramic samples then underwent the Their micro-structures, their crystal structures and the volumes of their pores were determined by equilibrium moisture content and water vapor adsorption/desorption and hygroscopic sorption properties of humidity control porous ceramics for 48 hours.

\section{MATERIALS AND MethodS}

The waste fiberglass and waste catalyst samples were oven-dried at $105^{\circ} \mathrm{C}$ for $24 \mathrm{~h}$ and ground in a ball mill to form fine powders (until pass through a 100 mesh sieve) suitable for pressing. The powder samples were mixed with each other to prepare a known mass percentage of waste fiberglass in catalyst in different concentration of waste fiberglass ( $0-40 \%$ by mass) to produce humidity control porous ceramic samples. The samples were compacted at $5 \mathrm{MPa}$ to form cylinder specimens $\left(51.8 \mathrm{~mm}{ }^{(\Phi)} \times 15 \mathrm{~mm}{ }^{(\mathrm{H})}\right)$ that were then desiccated before testing. The compacted humidity control porous ceramic specimens were placed on a platinum plate and burnt in an electrically heated furnace using a ramp rate of $5^{\circ} \mathrm{C} \mathrm{min}^{-1}$. The porous ceramic samples were then sintered at temperatures between $900^{\circ} \mathrm{C}$ and $1050^{\circ} \mathrm{C}$ for 120 minutes. The sintered samples were then cooled to room temperature and stored in a desiccator for subsequent physical properties testing and microstructure analyses. The chemical composition and physical characteristics of sampless were measured, using standard methods approved by the Taiwan Environmental Protection Administration (NIEA, 2004). The samples were digested using nitric acid $\left(\mathrm{HNO}_{3}\right)$ / perchloric acid $\left(\mathrm{HClO}_{4}\right)$ /hydrofluoric acid $(\mathrm{HF})$, according to NIEA $\mathrm{R} 355.00 \mathrm{C}$ and then analyzed with inductively coupled plasma atomic emission spectroscopy (ICP-AES) for their major elements. The NIEA R201.14C method, Toxicity Characteristic Leaching Procedure (TCLP), was used for heavy metal determination. Chemical composition: X-ray fluorescence (XRF) analysis was performed with an automated RIX 2000 spectrometer [15]. The specific surface area, specific pore volume and average pore diameter $(\mathrm{BJH}$ method) of the samples were measured by $\mathrm{N}_{2}$ adsorptiondesorption isotherms at $77 \mathrm{~K}$ using a surface area analyzer (Micromeritics, ASAP 2000).The adsorption/desorption efficiency were measured using the JIS A 1470 method [16], [17].

\section{RESUlTS AND DISCUSSION}

\section{A. Raw Material Characteristics}

Table I presents the compositions of the waste fiberglass and waste catalyst. The XRF analysis demonstrates that the major components of the waste fiberglass were $\mathrm{SiO}_{2}(65.4 \%)$, $\mathrm{CaO}(16.9 \%)$ and $\mathrm{Al}_{2} \mathrm{O}_{3}(11.7 \%)$. The next most abundant components were $\mathrm{MgO}(0.4 \%)$ and $\mathrm{K}_{2} \mathrm{O}(0.1 \%)$. The main components of the waste catalyst were $\mathrm{Al}_{2} \mathrm{O}_{3}(60.2 \%), \mathrm{SiO}_{2}$ $(34.5 \%)$ and $\mathrm{SO}_{3}(2.6 \%)$. The leaching concentrations of raw materials all met the regulatory thresholds (See Table II).

TABLE I: CHEMICAL COMPOSITION OF RAW MATERIALS

\begin{tabular}{ccc}
\hline \hline Composition & Waste Fiberglass & Waste Catalyst \\
\hline $\mathrm{SiO}_{2}(\%)$ & 65.4 & 34.53 \\
$\mathrm{Al}_{2} \mathrm{O}_{3}(\%)$ & 11.7 & 60.19 \\
$\mathrm{CaO}(\%)$ & 16.9 & 0.64 \\
$\mathrm{MgO}(\%)$ & 0.44 & 0.58 \\
$\mathrm{SO}_{3}(\%)$ & - & 2.55 \\
$\mathrm{~K}_{2} \mathrm{O}(\%)$ & 0.10 & 0.05 \\
$\mathrm{Cu}(\mathrm{mg} / \mathrm{kg})$ & 16.67 & N. D. \\
$\mathrm{Zn}(\mathrm{mg} / \mathrm{kg})$ & 47.62 & 88.00 \\
\hline \hline
\end{tabular}

TABLE II: METAL LEACHING CONCENTRATION OF RAW MATERIALS

\begin{tabular}{ccccccc}
\hline \hline TCLP (mg/L) & $\mathrm{Pb}$ & $\mathrm{Cr}$ & $\mathrm{Cu}$ & $\mathrm{Zn}$ & $\mathrm{Cd}$ & $\mathrm{Ni}$ \\
\hline Waste Fiberglass & N.D. & N.D. & 0.04 & 0.1 & N.D. & N.D. \\
Waste Catalyst & N.D. & N.D. & N.D. & N.D. & N.D. & 1.83 \\
\hline Regulatory Limits & 5 & 5 & 15 & - & 1 & - \\
\hline \hline
\end{tabular}

N.D.:Pb $<0.015$ mg/L; Cr $<0.009$ mg/L; Cd $<0.021$ mg/L;

\section{B. Flexural Strength of Humidity Control Porous Ceramics}

The flexural strength is the most important index for assuring the engineering quality of a building material. The results of the flexural strength tests on the humidity control porous ceramics made from the waste fiberglass and waste catalyst mixtures are shown in Fig. 1. All the humidity control porous ceramics samples showed a similar trend, that is, as the heating temperature increased to $750^{\circ} \mathrm{C}$ and $900^{\circ} \mathrm{C}$, the flexural strength of the brick gradually increased. When sintering temperature at $850^{\circ} \mathrm{C}$ and $900^{\circ} \mathrm{C}$, the flexural strength of humidity control porous ceramics almost met the CNS 3298 standards: i. e. $61.2 \mathrm{~kg} / \mathrm{cm}^{2}$ for ceramic nogging. It is concluded that waste fiberglass can be blended with waste catalyst in different proportions to produce good quality humidity control porous ceramics for sintering temperature at $850^{\circ} \mathrm{C}$ and $900^{\circ} \mathrm{C}$.

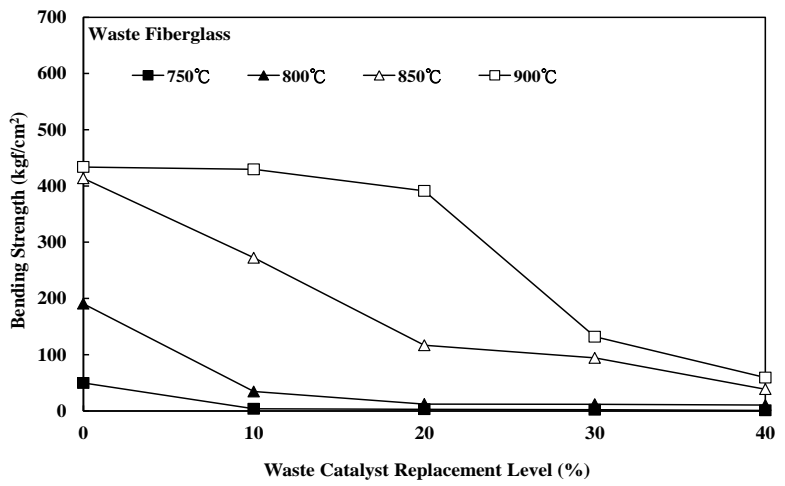

Fig. 1. Flexural strength of humidity control porous ceramics. 

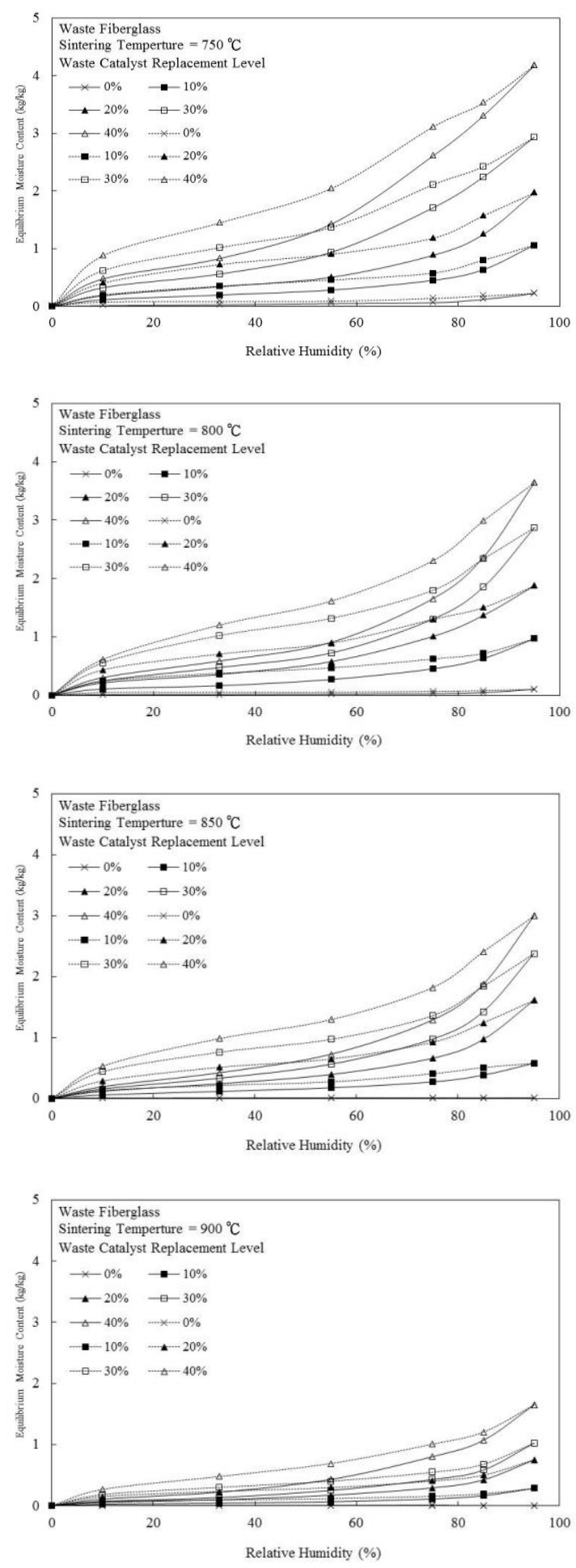

Fig. 2. Equilibrium moisture content of humidity control porous ceramics.

\section{Equilibrium Moisture Content of Humidity Control Porous Ceramics}

Fig. 2 shows the equilibrium moisture content of humidity control porous ceramics samples. The equilibrium moisture content values were highest, with $4.17 \mathrm{~kg} / \mathrm{kg}$ in the humidity control porous ceramics samples containing $40 \%$ waste catalyst samples at a relative humidity of $95 \%$. Nitrogen adsorption desorption isotherms showed a hydrophobic behavior (type $\mathrm{H}_{3}$ isotherm). When the heating temperature reached $900^{\circ} \mathrm{C}$, the humidity control porous ceramics samples containing $40 \%$ waste catalyst samples at a relative humidity of $95 \%$, the equilibrium moisture content values were $1.65 \mathrm{~kg} / \mathrm{kg}$. When the heating temperature reached $1050 \mathrm{oC}$, the humidity control porous ceramics samples containing $10-40 \%$ waste catalyst samples at a relative humidity of $95 \%$, The equilibrium moisture content values were $0.26-1.65 \mathrm{~kg} / \mathrm{kg}$.
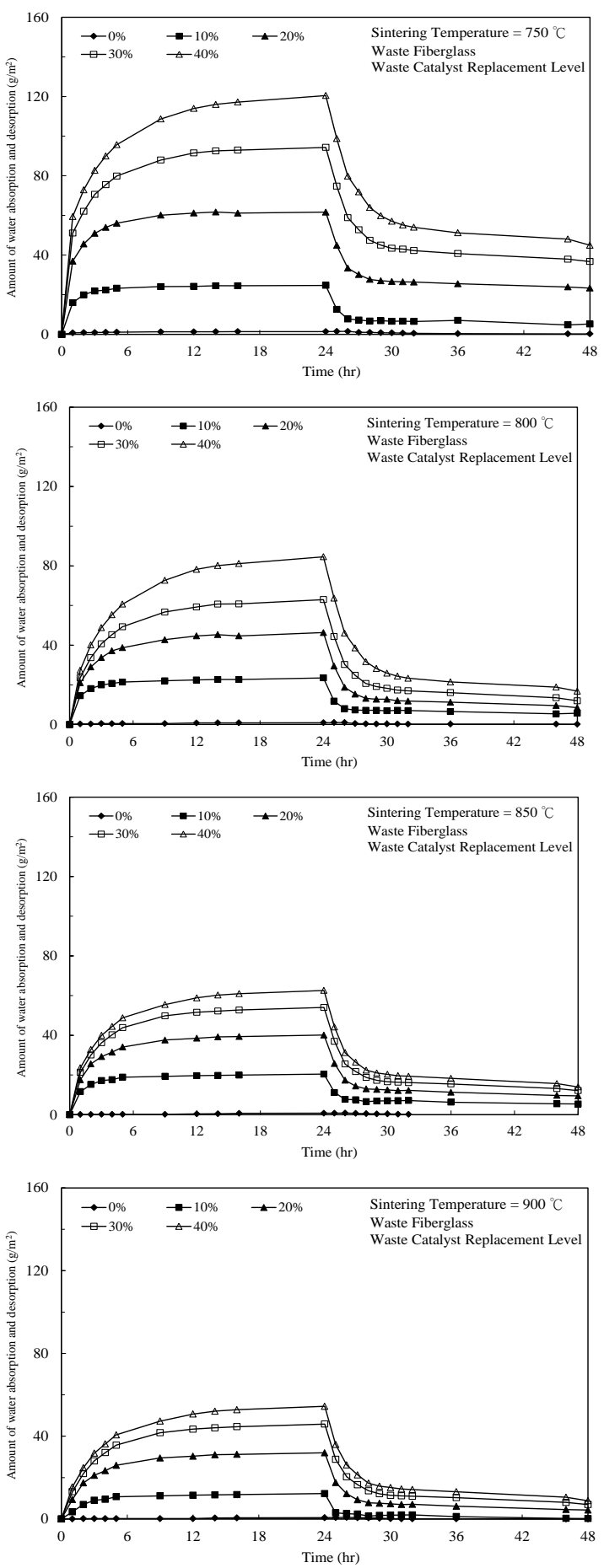

Fig. 3. Water vapor adsorption/desorption and hygroscopic sorption properties of humidity control porous ceramics for 48 hours.

\section{Water Vapor Adsorption/Desorption and Hygroscopic Sorption Properties of Humidity Control Porous Ceramics}

Fig. 3 shows the results of the water vapor adsorption/desorption and hygroscopic sorption properties of humidity control porous ceramics heated at various temperatures. As shown in Fig. 3, when the amount of waste catalyst was from $10 \%$ to $40 \%$, the water vapor 
adsorption/desorption was $24.69-120.49 \mathrm{~g} / \mathrm{cm}^{2}$ with respect to heating temperatures of $750^{\circ} \mathrm{C}$. The results indicated that the water vapor adsorption/desorption of the humidity control porous ceramics increased when the waste catalyst increased. Additionally, as the heating temperature increased, the water vapor adsorption/ desorption of the humidity control porous ceramics decreased. When the heating temperature increased, the pores of the humidity control porous ceramics decreased. When the humidity control porous ceramics made with less than $10-40 \%$ waste catalyst and heated to a temperature at $900^{\circ} \mathrm{C}$, the water vapor adsorption/desorption was 14.84-68.81 $\mathrm{g} / \mathrm{cm}^{2}$. The lower water vapor adsorption/desorption at the higher temperature $\left(900^{\circ} \mathrm{C}\right)$ suggests that local liquid-phase sintering occurred, which contributed to a decrease in the pore volume and thus the water vapor adsorption/desorption. When sintering temperature of $750-900^{\circ} \mathrm{C}$, humidity control porous ceramic (HCPC) samples for the waste fiberglass contained 10-30\% waste catalyst met JIS A1470 intensity specification of building materials $\left(>29 \mathrm{~g} / \mathrm{m}^{2}\right)$.

\section{CONCLUSION}

In this study, the following operating conditions are applied to developing humidity control porous ceramic products; a sintering temperature of $750-900^{\circ} \mathrm{C}$ and a percentage of waste fiberglass in waste catalyst of $0-40 \%$. Their micro-structures, their crystal structures and the volumes of their pores were determined by equilibrium moisture content and water vapor adsorption/desorption and hygroscopic sorption properties of humidity control porous ceramics for 48 hours. The leaching concentrations of raw materials all met the regulatory thresholds, it indicates that waste fiberglass and waste catalyst had potential as raw material for humidity control porous ceramics. The results indicated that the adsorption/ desorption performance of humidity control porous ceramic samples were strongly affected by the porosity and pore structure. Nitrogen adsorption/ desorption isotherms showed a hydrophobic behavior (type $\mathrm{H}_{3}$ isotherm). When sintering temperature of $850-900^{\circ} \mathrm{C}$, humidity control porous ceramic samples for the waste fiberglass contained $20-40 \%$ waste catalyst met JIS A1470 intensity specification of building materials $(>29$ $\mathrm{g} / \mathrm{m}^{2}$ ). A new humidity control porous ceramics with great a water vapor adsorption/desorption were developed by the waste fiberglass - waste catalyst mixtures.

\section{ACKNOWLEDGMENT}

The authors would like to thank the Ministry of Science and Technology (Republic of China, TAIWAN), for financially supporting this research under Contract No. NSC 101-2221-E-197-010-MY3 and MOST 104-2221-E-197 -003 -MY3.

\section{REFERENCES}

[1] A. López, M. I. Martín, I. G. Díaz, O. Rodríguez, F. J. Alguacil, and M. Romero, "Recycling of glass fibers from fiberglass polyester waste composite for the manufacture of glass-ceramic materials," J. Environ. Protection, vol. 3, pp. 740-747, 2012.
[2] Environmental Protection Administration Executive Yuan, R.O.C (Taiwan). The national industrial waste declaring amount reported by EPA in 2016.

[3] H. Cheng, K. L. Lin, R. Cui, C. L. Hwang, T. W. Cheng, and Y. M. Chang, "Effect of solid-to-liquid ratios on the properties of waste catalyst-Metakaolin based geopolymers," Constr. Build. Mater., vol. 88, pp. 74-83, 2015.

[4] K. L. Lin, C. L. Hwang, J. L. Shie, Y. M. Chang, and A Cheng, "Hydration characteristics of waste catalysts used as pozzolanic materials," Environ. Prog. Sustain. En., vol. 33, no. 2, pp. 353-358, 2014.

[5] K. L. Lin, T. C. Lee, J. C. Chang, and J. Y. Lan, "Water absorption and retention of porous ceramics co-sintered from waste diatomite and catalyst," Environ. Prog. Sustain. En., vol. 32, no. 3, pp. 641-648, 2013.

[6] K. L. Lin and H. L. Luo, "Evaluation of sintering characteristics of pavement tiles incorporating waste catalyst," Int. J. Pavement Res. Technol., vol. 2, no. 2, pp. 68-74, 2009

[7] K. L. Lin, K. W. Lo, M. J. Hung, C. L. Hwang, T. W. Cheng, and Y. M Chang, "Hydration characteristics of ecocement pastes produced from spent catalyst and waste sludge," Environ. Technol., 2016.

[8] T. W. Cheng, and Y. S. Chen, "On formation of $\mathrm{CaO}-\mathrm{Al}_{2} \mathrm{O}_{3}-\mathrm{SiO}_{2}$ glass-ceramics by verification of incinerator fly ash," Chemosphere vol. 51, pp. 817-824, 2003.

[9] A. L. Yurkov, T. A. Sarkisyan, D. A. Ivanov, and R. C. Bradt, "Final stages of sintering of ceramic materials: effect of residual porosity and microstructure on mechanical characteristics of surface," Ceram. Int. vol. 23, pp. 389-399, 1997

[10] P. A. Marchlewski, A. R. Olszyna, K. J. Kurzydlowski, and B. Ralph, "Grain growth in high-purity alumina ceramics sintered from mixtures of particles of different sizes," Ceramics International, vol. 25, pp. 157-163, 1999.

[11] B. Zhou and Z. Chen, "Experimental study on relation between micro-structure and macro-performance of zeolite-based humidity control building coating," Procedia Eng., vol. 121, pp. 1259-1265, 2015.

[12] H. Li, M. Ai, B. Liu, S. Zheng, and G. Zong, "Water vapor sorption on surfactant-templated porous silica xerogels," Micropor. Mesopor. Mater., vol. 143, no. 1, pp. 1-5, 2011

[13] S. B. Hong and E. G. Lear, "Pressure-induced hydration in zeolite tetranatrolite," Acta. Chim. Sinica., vol. 51, pp. 25-33, 2003.

[14] Y. Zhong and X. W. Cheng, "Studies on natural zeolite high-sillica and ultra-stable modification of framework," Acta. Chim. Sinica., vol. 63, pp. 1-8, 2005.

[15] K. L. Lin, J. C. Chang, J. L. Shie, H. J. Chen, and C. M. Ma, "Characteristics of porous ceramicsp produced from waste diatomite and water purification sludge," Environ. Eng. Sci., vol. 29, no. 6, pp. 436-446, 2012.

[16] JIS, "A 1470-1, Test method of adsorption/desorption efficiency for building material to regulate indoor humidity-Part 1: Response Method of Humidity,” Japanese Industrial Standards, Japan, 2002.

[17] H. J. Kim, S. S. Kim, Y. G. Lee, and K. D. Song, "The hygric performances of moisture adsorbing/desorbing building materials," Aerosol Air Quality Res., vol. 10, pp. 625-634, 2010.

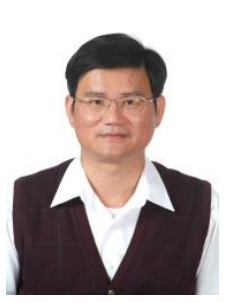

Kae-Long Lin is a professor in the Department of Environmental Engineering, National Ilan University, Taiwan, 26047, Republic of China. To pursue a research career in Pozzolanic reaction/ Eco-cement/ Waste Treatment/Management/ recycle/ E-waste recycle.

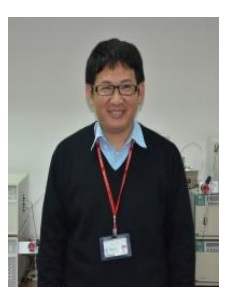

Chih-Ming Ma is a professor in the Department of Cosmetic Application \& Management, Saint Mary's Junior College of Medicine, Nursing and Management, Ilan, Taiwan, Republic of China. 


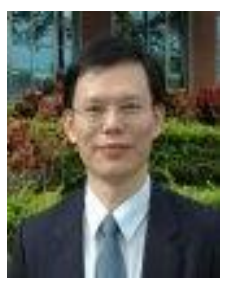

Huang-Mu Lo is a professor in the Department of Environmental Engineering and Management, Chaoyang University of Technology, Taichung, Taiwan Taichung, Taiwan, Republic of China.

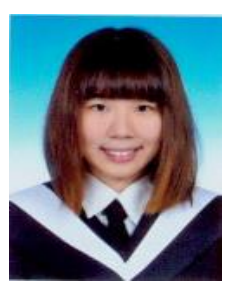

Ju-Ying Lan received the B.S. degree in environmental engineering from National I-Lan University, I-Lan, Taiwan, in 2007. She is a master in Deapertment of Environmental Engineering National Ilan University, Taiwan. 